\title{
Effect of the molecular weight of water-soluble chitosan on its fat-/cholesterol-binding capacities and inhibitory activities to pancreatic lipase
}

\author{
Qiu Jin ${ }^{1,2}$, Huahua Yu ${ }^{\text {Corresp., }}{ }^{1}$, Xueqin Wang ${ }^{1}$, Kecheng Li ${ }^{1}$, Pengcheng Li ${ }^{\text {Corresp. } 1}$ \\ ${ }^{1}$ Key Laboratory of Experimental Marine Biology, Institute of Oceanology, Chinese Academy of Sciences, Qingdao, Shandong, China \\ 2 University of Chinese Academy of Sciences, Beijing, Beijing, China \\ Corresponding Authors: Huahua Yu, Pengcheng Li \\ Email address: yuhuahua@qdio.ac.cn, pcli@qdio.ac.cn
}

Background. Obesity has become a worldwide burden to public health in recent decades. Given that obesity is caused by an imbalance between caloric intake and expenditure and that dietary fat is the most important energy source of all macronutrients (by providing the most calories), a valuable strategy for obesity treatment and prevention is to block fat absorption via the gastrointestinal pathway. In this study, the fat- and cholesterol-binding capacities and the inhibition of pancreatic lipase by water-soluble chitosan (WSC) with different weight-average molecular weight (Mw) were tested and compared in vitro, in order to determine the anti-obesity effects of WSC and the influence of its Mw.

Methods. In this study, WSC with different Mw ( 1000, 3000, 5000, 7000 and 9000 Da) were prepared by oxidative degradation assisted with microwave irradiation. A biopharmaceutical model of the digestive tract was used to determine the fat- and cholesterol-binding capacity of WSC samples. The pancreatic lipase assays were based on p-nitrophenyl derivatives.

Results. The results showed that all of the WSC samples exhibit great fat- and cholesterol-binding capacities. Within the testing range, $1 \mathrm{~g}$ of WSC sample could absorb 2-8 $\mathrm{g}$ of peanut oil or 50-65 mg of cholesterol, which are both significantly higher than the ability of cellulose to do the same. Meanwhile, all the WSC samples were proven to be able to inhibit pancreatic lipase activity to some extent.

Discussion. Based on the results, we suggest that there is a significant correlation between the binding capacity of WSC and its Mw, as WSC2 ( 3000 Da) shows the highest fat- and cholesterol-binding capacities (7.08 g.g-1 and $63.48 \mathrm{mg} . \mathrm{g}-1$, respectively), and the binding ability of WSC declines as its Mw increases or decreases from $3000 \mathrm{Da}$. We also suggest WSC as an excellent resource in the development of functional foods against obesity for its adsorption, electrostatic binding and entrapment of cholesterol, fat, sterols and triglycerides in the diet. 


\section{Effect of the molecular weight of water-soluble chitosan on}

2 its fat-/cholesterol-binding capacities and inhibitory

\section{3 activities to pancreatic lipase}

4 Qiu Jin ${ }^{1,2}$, Huahua $\mathrm{Yu}^{1,{ }^{1}}$, Xueqin Wang ${ }^{1}$, Kecheng $\mathrm{Li}^{1}$, Pengcheng $\mathrm{Li}^{1, *}$

$5 \quad{ }^{1}$ Key Laboratory of Experimental Marine Biology, Institute of Oceanology, Chinese Academy

6 of Sciences, Qingdao, Shandong, China

$7 \quad{ }^{2}$ University of Chinese Academy of Sciences, Beijing, Beijing, China

9 Corresponding Author:

10 Huahua $\mathrm{Yu}^{1}$

117 Nanhai Road, Qingdao, Shandong, 266071, China

12 Email address: yuhuahua@qdio.ac.cn

13 Pengcheng $\mathrm{Li}^{2}$

147 Nanhai Road, Qingdao, Shandong, 266071, China

15 Email address: pcli@qdio.ac.cn 


\section{Abstract}

Background. Obesity has become a worldwide burden to public health in recent decades. Given that obesity is caused by an imbalance between caloric intake and expenditure and that dietary fat is the most important energy source of all macronutrients (by providing the most calories), a valuable strategy for obesity treatment and prevention is to block fat absorption via the gastrointestinal pathway. In this study, the fat- and cholesterol-binding capacities and the inhibition of pancreatic lipase by water-soluble chitosan (WSC) with different weight-average molecular weight $(\mathrm{Mw})$ were tested and compared in vitro, in order to determine the anti-obesity effects of WSC and the influence of its Mw.

Methods. In this study, WSC with different $\mathrm{Mw}(\sim 1000, \sim 3000, \sim 5000, \sim 7000$ and $\sim 9000 \mathrm{Da})$ were prepared by oxidative degradation assisted with microwave irradiation. A biopharmaceutical model of the digestive tract was used to determine the fat- and cholesterol-binding capacity of WSC samples. The pancreatic lipase assays were based on p-nitrophenyl derivatives.

Results. The results showed that all of the WSC samples exhibit great fat- and cholesterol-binding capacities. Within the testing range, $1 \mathrm{~g}$ of WSC sample could absorb 2-8 $\mathrm{g}$ of peanut oil or 50 $65 \mathrm{mg}$ of cholesterol, which are both significantly higher than the ability of cellulose to do the same. Meanwhile, all the WSC samples were proven to be able to inhibit pancreatic lipase activity to some extent.

Discussion. Based on the results, we suggest that there is a significant correlation between the binding capacity of WSC and its Mw, as WSC2 ( 3000 Da) shows the highest fat- and cholesterolbinding capacities (7.08 g.g $\mathrm{g}^{-1}$ and $63.48 \mathrm{mg} \cdot \mathrm{g}^{-1}$, respectively), and the binding ability of WSC declines as its $\mathrm{Mw}$ increases or decreases from $3000 \mathrm{Da}$. We also suggest WSC as an excellent resource in the development of functional foods against obesity for its adsorption, electrostatic binding and entrapment of cholesterol, fat, sterols and triglycerides in the diet.

\section{Introduction}

The prevalence of obesity, caused by an imbalance between caloric intake and expenditure, has 
54

55

56

57

58

59

60

61

62

dramatically risen in recent years (Racette et al., 2003; Ogden et al., 2014). According to the WHO report of 2009, more than 1 billion people are overweight worldwide, and at least 400 million of them are defined as obese (Rodgers et al., 2012). Obesity was defined as a worldwide chronic disease by WHO in 2004 and has been proven to be a major risk factor for developing other diseases such as hyperlipidemia, hypertension, type 2 diabetes, cardiovascular diseases, and certain cancers (Saltiel \& Kahn 2001; Rahmouni et al., 2005; Vucenik \& Stains 2012; Bastien et al., 2014; Tobias et al., 2014). One of the principal research interests in food science in recent years has been the extraction and identification of natural-derived bioactive compounds with anti-obesity effects.

Chitosan (CTS), a polyglucosamine derived from chitin, is one of these attractive compounds. As the second most abundant polysaccharide in nature, chitosan locates mainly in the exoskeletons of arthropods, such as crabs, lobsters, shrimps and insects (Hu et al., 2016). As a dietary fiber, chitosan cannot be digested by the digestive enzymes of humans. Although the specific mechanism remains controversial, there are already lots of studies indicate that chitosan is effective in obesity treatment. For example, a mixture of chitin (20\%) and chitosan (80\%) was proved to be able to prevent the increase of body weight of diet-induced obese mice via enhancing fat excretion and inhibiting lipid absorption (Han et al., 1999). In a study of human obesity, the chitosan group demonstrated more body weight loss and improved body composition index, compared with the placebo control (Kaats et al., 2006). However, there are also studies indicating that taking waterinsoluble chitosan with high molecular weight (Mw) simply would cause side effects such as nausea and constipation (Sumiyoshi \& Kimura 2006; Neyrinck et al., 2009; Qinna et al., 2013). Water-soluble chitosan (WSC) is a derivative of chitosan. Studies have proven that WSC has a higher reactivity and fewer side effects than water-insoluble chitosan in reducing food absorption (Choi et al., 2002). Meanwhile, the study of Choi et al. (2002) also reported an improvement in the ovarian and oviduct dysfunction in mice that were fed a high-fat diet. Due to its significant advantages, including biocompatibility, nontoxic nature and high solubility in neutral aqueous solutions, WSC is considered as an ideal lipid-lowering dietary supplement.

The weight-average molecular weight $(\mathrm{Mw})$ of chitosan is an important characteristic that 
81

82

greatly affects its chemical and physiological properties. The $\mathrm{Mw}$ of chitosan is proportional to its viscosity. And there are studies proving that viscous polysaccharides can cause entrapments, which would reduce the absorption of fat and cholesterol in the diet (Kanauchi et al., 1995). However, given the wide range of chitosan $\mathrm{Mw}$, studies about the relationship between the $\mathrm{Mw}$ of chitosan and its anti-obesity effect are less reported and unsystematic. There have been studies suggesting that low-Mw chitosan oligosaccharide (COS) (1000-3000 Da) is more effective than high-Mw COS in anti-obesity function by inhibiting adipocyte differentiation in 3T3-L1 cells (Kumar et al., 2009; Rahman et al., 2008). In addition, the results of another study suggested that the $46000 \mathrm{Da}$ chitosan was more effective than chitosan of 21000 or $130000 \mathrm{Da}$ in anti-obesity function by inhibiting pancreatic lipase activity (in vitro) and plasma triacylglycerol elevation in the oral lipid tolerance test (Sumiyoshi \& Kimura 2006). Therefore, further research is necessary to systematically investigate the relationship between chitosan $\mathrm{Mw}$ and its anti-obesity effect.

Current therapies of obesity mainly include appetite control, blocking fat absorption, stimulating energy expenditure, suppressing adipose tissue growth and increasing body fat mobilization $\mathrm{Hu}$ et al., 2016). Dietary fat is the most important energy source of all macronutrients, providing the most calories. It has been demonstrated that there is a direct relation between dietary fat intake and obesity onset (Hu et al., 2016). Therefore, it is a valuable strategy for obesity treatment and prevention by blocking fat absorption via the gastrointestinal pathway. It has been proven that sufficient fiber, such as cellulose, in the diet could reduce weight by preventing excessive fat intake and fat accumulation in adipose depots (Van Itallie 1978). WSC has also been suggested as an ideal lipid-lowering dietary supplement due to its effective fat-/cholesterol-binding capacity, biocompatibility, nontoxic nature and facile solubility in neutral aqueous solutions (Anraku et al., 2009). Pancreatic lipase (PL) is a key enzyme for the absorption of dietary triglycerides. It rapidly converts a triglyceride into a 2-monoglycerol and two free fatty acids (Gu et al., 2011). Given the key role PL plays in starch and lipid digestion, it represents an attractive target for the prevention of excessive body weight gain. Orlistat, a potent competitive inhibitor of PL, is currently available as an anti-obesity drug. Although it has been reported that orlistat showed a significant weight- 
108

109

110

111

112

113

114

115

116

117

118

119

120

121

122

123

124

125

126

127

128

129

130

131

132

133

134

reducing effect over both short- and long-term periods, there were also some harmful gastrointestinal side effects reported, including loose stools and oily stools/spotting (Derosa et al., 2005). WSC was also proven to be able to inhibit pancreatic lipase, and the inhibitory effect was suggested to be related to its Mw (Tsujita et al., 2007). However, the underlying mechanism is still not understood, and there are few related reports; thus, further studies are needed.

In the present study, the fat-binding and cholesterol-binding capacities of WSC with different Mw, as well as its inhibitory effects on PL, were tested and compared in order to determine the anti-obesity effects of WSC and the influence of its Mw.

\section{Materials and Methods}

\subsection{Materials and equipment}

Chitosan (referred as CTS0, Mw of $\sim 1,800,000 \mathrm{Da}$, the degree of deacetylation was $82 \%$ ) from shrimp shell was purchased from Baicheng Biochemical Corp (Qingdao, China). The microwave synthesis/extraction reaction station was purchased from SINEO Microwave Chemistry Technology Co., Ltd. (Shanghai, China). The oscillation incubator (ZQLY-180F) was purchased from Shanghai Zhichu Instruments Co., Ltd. (Shanghai, China). The total cholesterol assay kit was purchased from Nanjing Jiancheng Bioengineering Institute. Lipase (from beef pancreas, powder, 15-35 units/mg) was purchased from the Aladdin Industrial Corporation (Shanghai, China). $\mathrm{H}_{2} \mathrm{O}_{2}$ and other reagents were of analytical reagent grade.

\subsection{Preparation of WSC with Mw of $\sim 1000, \sim 3000, \sim 5000, \sim 7000$ and $\sim 9000$ Da}

WSC samples with Mw of $\sim 1000, \sim 3000, \sim 5000, \sim 7000$ and $\sim 9000$ Da were prepared by the method of Li et al. (2012) with some modifications. In brief, $5 \mathrm{~g}$ of CTS0 was introduced to 250 $\mathrm{mL}$ of $2 \%$ acetic acid, and then $5 \mathrm{~mL}$ of $30 \% \mathrm{H}_{2} \mathrm{O}_{2}$ was added. Afterwards, the microwave-assisted degradation was carried out at a power of $600 \mathrm{~W}$ at $70{ }^{\circ} \mathrm{C}$ for $60,32,30,22$ and $18 \mathrm{~min}$, respectively. Immediately after the reaction, the reaction mixture was cooled to room temperature, and the $\mathrm{pH}$ was adjusted to 7.0 with aqueous $\mathrm{NaOH}$ solution $(10 \mathrm{~mol} / \mathrm{L})$. The degraded products were then precipitated by adding ethanol. Finally, the precipitate was collected by centrifugation for $10 \mathrm{~min}$ at $3740 \times \mathrm{g}$ and lyophilized to yield powdered products. The products that were degraded 
135

136

137

138

139

140

141

142

143

144

145

146

147

148

149

150

151

152

153

154

155

156

157

158

159

160

161

for $60,32,30,22$ and 18 min were referred as WSC1-5, respectively.

\subsection{Characterization}

The weight-average molecular weight (Mw) of WSC1-5 were measured by the method of Zou et al. (2015) with some modifications. In brief, the Mw was measured by an Agilent 1260 gel permeation chromatography (Agilent Technologies, USA) equipped with a refractive index detector. Chromatography was performed on TSK G3000-PWXL columns at a column temperature of $30^{\circ} \mathrm{C}$, a flow rate of $0.8 \mathrm{~mL} / \mathrm{min}$, and a $\mathrm{CH}_{3} \mathrm{COOH}(0.2 \mathrm{~mol} / \mathrm{L}) / \mathrm{CH}_{3} \mathrm{COONa}(0.1$ $\mathrm{mol} / \mathrm{L})$ aqueous solution was used as mobile phase. The sample concentration was $0.3 \%(\mathrm{w} / \mathrm{v})$. Dextrans (Sigma, USA) with Mw of 1000, 5000, 12000, 25000 and 50000 Da were used to calibrate the column.

Fourier transform infrared (FT-IR) spectra of CTS0 and the degraded chitosan were measured in the $4000-400 \mathrm{~cm}^{-1}$ regions using a Thermo Scientific Nicolet iS10 FT-IR spectrometer in $\mathrm{KBr}$ discs.

\subsection{Estimation of the fat-binding capacity of WSC}

The fat-binding capacity was evaluated in vitro by the method of Zhang et al. (2012) with some modifications. Briefly, $120 \mathrm{mg}$ of WSC was mixed with $10 \mathrm{~mL}$ of $\mathrm{HCl}(0.1 \mathrm{~mol} / \mathrm{L})$. After addition of $10 \mathrm{~g}$ of peanut oil, the mixture was swirled thoroughly and incubated at $37^{\circ} \mathrm{C}$ with shaking $(300$ $\mathrm{rpm})$. After $2 \mathrm{~h}$ of incubation, the $\mathrm{pH}$ of the mixture was adjusted to the range of 7.0-7.60 by adding $\mathrm{NaOH}(1 \mathrm{~mol} / \mathrm{L})$. Then, the resulting mixture was incubated for another $2 \mathrm{~h}$ at $37^{\circ} \mathrm{C}$ and $300 \mathrm{rpm}$. Afterwards, it was cooled to room temperature and centrifuged at $3740 \times \mathrm{g}$ for $20 \mathrm{~min}$. The supernatant oil, considered an unbound oil, was carefully and quantitatively removed. To release the oil bound by WSC while it was in alkaline solution and to dissolve the WSC, $\mathrm{HCl}$ solution $(0.1 \mathrm{~mol} / \mathrm{L})$ was added to the WSC-water layer until the $\mathrm{pH}$ was 3.0 . Afterwards, double extraction with ethyl ether was used to remove the released oil. Then, the combined ether extracts were kept at $40{ }^{\circ} \mathrm{C}$ until the ether had completely evaporated. At last, the remaining oil was weighed, and this mass was used to calculate the fat-binding capacity of WSC. The fat-binding capacity of the WSC sample was expressed as grams of bound oil per gram of WSC. Cellulose 
162

163

164

165

166

167

168

169

170

171

172

173

174

175

176

177

178

179

180

181

182

183

184

185

186

187

188

was used as a positive control, and the solution without WSC was used as a substrate blank. The test was conducted in triplicate. Scanning electron microscope (SEM) image and FT-IR spectra were used to identify the structure and composition of the precipitate that was collected after centrifugation.

\subsection{Estimation of the cholesterol-binding capacity of WSC}

The cholesterol-binding capacity was evaluated in vitro by the method of Liu et al. (2008) with some modifications. First, a cholesterol micellar solution was prepared by sonication; every $1 \mathrm{~mL}$ sample contained $10 \mathrm{mM}$ sodium taurocholate, $2 \mathrm{mM}$ cholesterol, $5 \mathrm{mM}$ oleic acid, $132 \mathrm{mM} \mathrm{NaCl}$, and $15 \mathrm{mM}$ sodium phosphate buffer ( $\mathrm{pH}$ 7.4). Then, $60 \mathrm{mg}$ of WSC was added to $5 \mathrm{~mL}$ of the micellar solution. The mixture was incubated for $2 \mathrm{~h}$ in a $37^{\circ} \mathrm{C}$ shaker bath. Then, the mixture was transferred to a centrifuge tube and centrifuged at $23294 \times \mathrm{g}$ for $20 \mathrm{~min}$ at $37^{\circ} \mathrm{C}$. The supernatant was collected for the determination of cholesterol. The amount of binding was calculated as the amount of cholesterol in the supernatant of the substrate blank subtracted from the amount in the supernatant of the sample. The amount of cholesterol was determined by the total cholesterol assay kit. The binding capacity of WSC was calculated as the milligrams of bound cholesterol per gram of WSC. Cellulose was used as a positive control, while the micellar solution without WSC was used as a substrate blank. The test was conducted in triplicate. SEM image and FT-IR spectra were used to identify the structure and composition of the precipitate that was collected after centrifugation.

\subsection{Assay of the inhibitory effects of WSC on the pancreatic lipase}

The assay of the inhibitory effect on pancreatic lipase in vitro was measured by the method of Margesin et al. (2002) with some modifications. First, a calibration curve of the concentration and absorbance at $405 \mathrm{~nm}$ of pNP was prepared. Standards containing 0 (reagent blank), 25, 50, 75, 100 and $125 \mu \mathrm{g}$ of $\mathrm{pNP}$ were made by adjusting 0 to $1.25 \mathrm{~mL}$ of a working standard solution to 5 $\mathrm{mL}$ with buffer. The absorption of pNP was measured spectrophotometrically at $405 \mathrm{~nm}$ against the reagent blank. A calibration curve relating the concentration and absorbance of pNP was obtained. Then, $700 \mu \mathrm{L}$ of Tris-HCL buffer (50 mM, pH 8), $100 \mu \mathrm{L}$ of WSC sample and $100 \mu \mathrm{L}$ 
189

190

191

192

193

194

195

196

197

198

199

200

201

202

203

204

205

206

207

208

209

210

211

212

of pancreatic lipase solution of a certain concentration were prewarmed at $37^{\circ} \mathrm{C}$ in a water bath for $10 \mathrm{~min}$. Afterwards, $100 \mu \mathrm{L}$ of substrate solution (a certain amount of p-nitrophenyl butyrate (pNPB) that was diluted in dimethyl sulfoxide (DMSO) and stored at $-20{ }^{\circ} \mathrm{C}$ ) were added. The contents were mixed, and the tubes were incubated in the water bath at $37^{\circ} \mathrm{C}$ for exactly 15 min. Then, the tubes were cooled for $10 \mathrm{~min}$ on ice immediately to stop the reaction. Afterwards, the tube contents were centrifuged at $3740 \times \mathrm{g}$ and in the range of 2 to $4{ }^{\circ} \mathrm{C}$ for $5 \mathrm{~min}$. The supernatants were pipetted into test tubes that were held on ice. Immediately afterwards, the absorption of the released pNP was measured spectrophotometrically at $405 \mathrm{~nm}$ against the reagent blank. The concentration of pNP could be obtained by referencing the calibration curve. Orlistat was used as a positive control. One unit of PL activity was defined as the amount of the enzyme that releases $1 \mu \mathrm{mol}$ of $\mathrm{pNP}$ in $1 \mathrm{~min}$ under certain conditions $(\mathrm{U} / \mathrm{mL})$. The activity of PL was calculated by the following formula:
PL activity $=\frac{\mathrm{CV}^{\prime}}{\mathrm{TV}^{\prime}}$

where PL activity is one unit of PL activity, in $\mathrm{U} / \mathrm{mL}$; $\mathrm{C}$ is the concentration of $\mathrm{pNP}$, in $\mu \mathrm{mol} / \mathrm{mL}$; $\mathrm{V}$ is the final volume of the reaction, in $\mathrm{mL}$; $\mathrm{T}$ is the reaction time, in min; and $\mathrm{V}^{\prime}$ is the volume of the PL, in $\mathrm{mL}$.

The inhibition rate (\%) was calculated by the following formula:

$$
\text { Inhibition rate }(\%)=100-\left(\frac{\mathrm{B}-\mathrm{b}}{\mathrm{A}-\mathrm{a}} \times 100\right)
$$

where $\mathrm{A}$ is the PL activity without inhibitor, a is the negative control without inhibitor, $\mathrm{B}$ is the PL activity with inhibitor, and $\mathrm{b}$ is the negative control with inhibitor.

The reaction speed $(\mathrm{mmol} / \mathrm{L} / \mathrm{s})$ was calculated by the following formula:

$$
v=\frac{A_{405 n m}}{\varepsilon \times 10^{-3} \times t}
$$

where $v$ is the reaction speed, in $\mathrm{mmoL} / \mathrm{L} / \mathrm{s} ; \mathrm{A}_{405 \mathrm{~nm}}$ is the absorbance of the released $\mathrm{pNP}$ measured spectrophotometrically at $405 \mathrm{~nm} ; \varepsilon$ is the extinction coefficient of the released pNP, in 
213

214

215

216

217

218

219

220

221

222

223

224

225

226

227

228

229

230

231

232

233

234

235

236

237

238

239

$\mathrm{L} /(\mathrm{mol} \mathrm{cm})$. The extinction coefficient of $\mathrm{pNP}$ at $405 \mathrm{~nm}$ is $18800(\mathrm{~L} / \mathrm{moL} / \mathrm{cm}) ; \mathrm{t}$ is the reaction time, in $\mathrm{s}$.

\subsection{Statistical analysis}

All data are expressed as the mean \pm SD. Differences between groups were determined by oneway analysis of variance, using SPSS 17.0. Results were considered significant if the value of $p$ was $<0.05$.

\section{Results and Discussion}

\subsection{Degradation of chitosan by hydrogen peroxide under microwave irradiation}

The degradation products of chitosan are complex mixtures. The weight-average molecular weights (Mw) of WSC1-5 were measured by high-performance liquid chromatography (HPLC). HPLC determination of Mw could standardize the mixtures and provide relative quantitative parameters that could feasibly be used for comparisons. Fig. 1 shows changes of Mw of chitosan with different reaction times. These tests were carried out in the presence of $\mathrm{H}_{2} \mathrm{O}_{2}$ at $70{ }^{\circ} \mathrm{C}$ and a microwave power of $600 \mathrm{~W}$. CTS0, with Mw of $1800000 \mathrm{Da}$, was used as an ingredient. The Mw of degraded products decreased quickly at the beginning and could reach $\sim 9000 \mathrm{Da}$ in $18 \mathrm{~min}$. WSC with a low Mw of $\sim 1000$ Da were obtained when the degradation time reached 60 min. In addition, at that point, the change in Mw was no longer obvious. The HPLC figures show that the Mw of the degradation products after 60, 32, 30, 22 and 18 min (referred as WSC1-5) of irradiation were 1294.3, 3135.6, 4951.9, 7312.8 and 9304.3 Da, respectively (Fig. 2).

Fig. 3 showed the FT-IR spectra of the degraded chitosan and the original chitosan (CTS0). It could be observed that the characteristic absorption bands of CTS0 were appeared at $1641.29 \mathrm{~cm}^{-1}$ (Amide I), $1599.81 \mathrm{~cm}^{-1}\left(\mathrm{NH}_{2}\right.$ bending) and $1327.60 \mathrm{~cm}^{-1}$ (Amide III). The bands in the range 1158-895 $\mathrm{cm}^{-1}$ were assigned to the characteristics of its polysaccharide structure (Peniche et al., 1999). Compared with the FT-IR spectra of CTS0, the spectra of the degraded chitosan exhibited most of the bands as CTS0, indicating that the main polysaccharide structure of the degraded chitosan still remained. However, there still existed some differences between the degraded chitosan and CTS0. For example, bending and stretching of $\mathrm{N}-\mathrm{H}$ and $\mathrm{O}-\mathrm{H}$ shifted to low wave 
240

241

242

243

244

245

246

247

248

249

250

251

252

253

254

255

256

257

258

259

260

261

262

263

264

265

266

number, which indicated that the intermolecular and intramolecular hydrogen bonds of chitosan were weakened. Meanwhile, $1327.60 \mathrm{~cm}^{-1}$ (Amide III) also shifted to low wave number, indicating that with the decrease of the molecular weight of chitosan, the free amino group numbers of degraded products decreased.

WCS with different Mw can be obtained by a variety of techniques, such as acid hydrolysis, oxidative degradation and enzymatic methods (Chang et al., 2001; Muzzarelli et al., 2002; Trombotto et al., 2008; Aam et al., 2010). All of these techniques have advantages as well as disadvantages. For example, the acid hydrolysis of chitosan not only requires special equipment with corrosion resistance to concentrated acid but also has major waste disposal problems. The enzymatic methods do not require special equipment, but the cost of enzymes is rather high. Oxidative degradation is easily available and environmentally friendly. The depolymerization caused by free radical reactions dominates. However, the use of $\mathrm{H}_{2} \mathrm{O}_{2}$ alone makes the formation of free radicals inefficient, resulting in a slow degradation of chitosan. Meanwhile, there are some side reactions that can change the chemical structure of chitosan. In recent years, microwaveassisted oxidative degradation has received increasing attention due to its remarkable advantages, including lower concentrations of $\mathrm{H}_{2} \mathrm{O}_{2}$, lower temperatures and shorter reaction times compared with conventional heating modes (Li et al., 2012).

\section{Figure 1 approximately here}

\section{Figure 2 approximately here}

\section{Figure 3 approximately here}

\subsection{Fat- and cholesterol-binding capacity of WSC}

In this study, five WSC samples with the same degree of deacetylation and different Mw ( 1000, $\sim 3000, \sim 5000, \sim 7000$, and $\sim 9000 \mathrm{Da})$ were used to identify the relationship between the fat/cholesterol-binding capacity of WSC and its Mw (<10000 Da). A biopharmaceutical model of the digestive tract was used to show the fat- and cholesterol-binding capacity of WSC samples. As the results show, within the testing range, $1 \mathrm{~g}$ of WSC could absorb 2-8 $\mathrm{g}$ of peanut oil (Fig. 4) or 50-65 mg of cholesterol (Fig. 5), of which both numbers are significantly higher than that of 
267

268

269

270

271

272

273

274

275

276

277

278

279

280

281

282

283

284

285

286

287

288

289

290

291

292

293

cellulose. WSC2 showed the highest peanut oil-binding capacity, which was $7.08 \mathrm{~g}^{-1} \mathrm{~g}^{-1}$, which is much higher than its affinity for cellulose $\left(0.41 \mathrm{~g} \cdot \mathrm{g}^{-1}\right)$. The peanut oil-binding capacity of WSC3 was the second highest and was not significantly different from that of CTS0. In addition, there were no pronounced differences between the capacities of WSC1, WSC4 and WSC5. For the cholesterol-binding capacity, a similar trend was that WSC2 and WSC3 showed the highest cholesterol-binding capacities of $63.48 \mathrm{mg} \cdot \mathrm{g}^{-1}$ and $62.91 \mathrm{mg} \cdot \mathrm{g}^{-1}$, respectively. WSC1 followed, while WSC4 and WSC5 had the least capacity. It was worth mentioning that all the WSC samples showed higher cholesterol-binding capacities than CTS0, and all the chitosan samples, including CTS0 and WSC1-5, showed significantly higher cholesterol-binding capacities than cellulose. The SEM image shows that WSC2 has a homogeneous and irregular shape (Fig. 6A), while the SEM images of the precipitate formed by WSC2 and peanut oil (Fig. 6B) or cholesterol (Fig. 6D) present irregular, rugged, nubbly shapes. Obvious microspheres were also seen (Fig. 6C and 6E). The FTIR spectra of WSC2, peanut oil and their precipitate are shown in Fig. 7, while the FT-IR spectra of WSC2, cholesterol and their precipitate are shown in Fig. 8. The characteristic absorption bands of WSC2 appeared at $1574.32 \mathrm{~cm}^{-1}\left(\mathrm{NH}_{2}\right.$ bending vibration) and $1415.31 \mathrm{~cm}^{-1}$ (Amide III). The bands in the range of $1158-895 \mathrm{~cm}^{-1}$ were assigned to characteristics of the polysaccharide structure (Fig. 7a and 8a) (Peniche et al., 1999). The characteristic absorption bands of peanut oil appeared at 2970-2850 $\mathrm{cm}^{-1}$ (C-H symmetric or asymmetric.), $1746.49 \mathrm{~cm}^{-1}$ ( $\mathrm{RC}=\mathrm{OOR}$ stretching vibration) and $1162.90 \mathrm{~cm}^{-1}$ (C-C stretching vibration) (Fig. 7b) (Alexa et al., 2009). The characteristic absorption bands of both WSC2 and peanut oil were observed in the precipitate (Fig. 7c), proving that both WSC2 and peanut oil are included in the precipitate. The characteristic absorption bands of cholesterol appeared at $3297.10 \mathrm{~cm}^{-1}(\mathrm{O}-\mathrm{H}$ stretching vibration) and 1052.37 $\mathrm{cm}^{-1}$ (C-O stretching vibration). The bands in the ranges of $3000-2850 \mathrm{~cm}^{-1}$ and $1464-1340 \mathrm{~cm}^{-1}$ were assigned to the characteristics of the C-H (Fig. 8b) (Deleris \& Petibois 2002). The FT-IR spectra of the precipitate (Fig. 8c) shows that there are characteristic absorption bands of both WSC2 and cholesterol, indicating that both WSC2 and cholesterol are included in the precipitate. According to all these results, we suggest that WSC has the ability to form micelles and to trap the 
294

295

296

297

298

299

300

301

302

303

304

305

306

307

308

309

310

311

312

313

314

315

316

317

318

319

320

oil phase and cholesterol upon precipitation.

Electrostatic effects, embedding and adsorption are usually considered the three main mechanisms of chitosan's fat- and cholesterol-binding capacities (Czechowska-Biskup et al., 2005; Liu et al., 2008). As a weak cationic polyelectrolyte, chitosan is soluble in aqueous solutions of inorganic and organic acids, forming strongly charged macromolecules. Therefore, when it is eaten together with fat and cholesterol, in the condition of the stomach with a soluble $\mathrm{pH} 2$, the ionized polycationic chitosan would form complexes and micelles with negatively charged molecules and particles, such as triglycerides, fatty and bile acids, cholesterol and other sterols. As a result, the complexes and micelles would not be absorbed. The molecular conformation, charge density and distribution along the chain will contribute to the effectiveness of this binding. However, due to the deprotonation of the amino groups, chitosan precipitates when the $\mathrm{pH}$ rises above 6.5. So, as digestion progresses and the $\mathrm{pH}$ rises in the solutions of duodenum and intestine, chitosan molecules lose their charge and precipitate with trapped micelles and fat microdroplets. As a result, the excretion of fatty materials, including cholesterol, sterols and triglycerides, is promoted. This conclusion is verified by the studies of Xia et al. (2011). By measuring the content of fluorescein-isothiocyanate-labeled chitosan (FITC-CIS) in plasma and tissues following oral administration of FITC-CIS in mice, Xia et al. (2011) deduced that chitosan could directly bind dietary fat in the digestive tract and then be excreted with the feces, and a fraction of the chitosan was degraded into chitosan oligosaccharide to regulate lipid metabolism. Sufficient fiber, such as cellulose, in the diet was accepted by the public as an ideal diet food that reduces weight (Van Itallie 1978; Howarth et al., 2001; Slavin 2005; Anraku et al., 2009). The anti-obesity effect of cellulose mainly depends on decreasing the caloric density of the diet, slowing the rate of food ingestion, increasing the effort involved in eating, promoting intestinal satiety and interfering slightly with efficiency of energy absorption. Its adsorption ability in vitro mainly depends on having physical adsorption that is much weaker than that of chitosan. In contrast, chitosan shows a higher fat- and cholesterol-binding capacity than cellulose in vitro.

The result also indicates that the Mw of WSC plays an important role in its fat- and cholesterol- 
321 binding capacity. Although no convincing data have been published that present a straightforward 322 dependence between the fat-/cholesterol-binding ability of chitosan and its Mw, previous studies

323 have suggested a general tendency that lowering the Mw of chitosan leads to an increase in their 324 fat-/cholesterol-binding capacity (Wojtasz-Pajak et al., 1998; Czechowska-Biskup et al., 2005). 325 On the one hand, shorter chains, which have a higher mobility (such as WSC2 ( 3000 Da)), may 326 be more effective in forming or occluding micelles. In addition, when the chain becomes longer, 327 such as the cases of WSC4-5 ( 7000-9000 Da), the mobility decreases, which is disadvantageous 328 for micelle formation. However, on the other hand, if the chains become too short, such as the case of WSC1 ( 1000 Da), their solubility at pH 7 would increase. As a result, they would probably tend to form individual solubilized molecules rather than oil- and cholesterol-trapping micelles and/or matrices. This hypothesis was verified by this study, as WSC2 ( 3000 Da) shows the highest binding capacity. In addition, the binding capacity decreased as the Mw increased or decreased.

\section{Figure 4 approximately here}

\section{Figure 5 approximately here}

\section{Figure 6 approximately here}

\section{Figure 7 approximately here}

\section{Figure 8 approximately here}

\subsection{Inhibition of pancreatic lipase}

3.3.1 Estimation of the optimum reaction temperature, $\mathrm{pH}$, substrate concentration, enzyme concentration and the addition order of the substrate, enzyme, and inhibitor

The appropriate methodological strategy to characterize an inhibitor depends on the type of inhibitor. In addition, it is particularly important to know which substrate concentrations constitute saturating conditions for the enzyme. Therefore, in order to identify the PL inhibitory ability of WSC accurately, the optimum reaction temperature, $\mathrm{pH}$, substrate concentration, enzyme concentration and the addition order of substrate, enzyme and inhibitor were determined (Fig. 9).

As Fig. 9A showed, an increase in the temperature of incubation from 30 to $37^{\circ} \mathrm{C}$ significantly 
348 increased lipase activity $(\mathrm{U} / \mathrm{mL})$ The highest activity was measured at $37^{\circ} \mathrm{C}$. To standardize the 349 method, a temperature of $37^{\circ} \mathrm{C}$ was chosen because the most precise result (lowest standard 350 deviations) was obtained at this temperature; $37^{\circ} \mathrm{C}$ was also the normal body temperature at which 351 pancreatic lipase played a role.

352 Lipase activity $(\mathrm{U} / \mathrm{mL})$ increased with increasing $\mathrm{pH}$ in the range from 6-8. At $\mathrm{pH} 9.0$, a rapid

353

354 decrease of enzyme activity due to enzyme denaturation was observed. Enzyme assays based on p-nitrophenyl derivatives were usually carried out at a $\mathrm{pH}$ of 7.25 to 8.0 according to other studies (Feller et al., 1991; Ishimoto et al., 2001). In this study, pH 8.0 was used as the optimum pH, as Fig. 9B showed.

The relationship between substrate concentration and reaction speed was measured in this study. An increase in the substrate concentration from $2-14 \times 10^{-4} \mathrm{~mol} / \mathrm{L}$ increased reaction speeds, as Fig. 9C showed. However, when the substrate concentration was more than $10 \times 10^{-4} \mathrm{~mol} / \mathrm{L}$, the change was no longer apparent. To standardize the method, a substrate concentration of $10 \times 10^{-4} \mathrm{~mol} / \mathrm{L}$ was chosen for all further analyses.

As Fig. 9D showed, there was an increase of the reaction speed when the enzyme concentration increased from $0.1-0.7 \mathrm{mg} / \mathrm{mL}$. In addition, when the lipase concentration was more than 0.5 $\mathrm{mg} / \mathrm{mL}$, the change became no longer apparent. Therefore, a lipase concentration of $0.5 \mathrm{mg} / \mathrm{mL}$ was chosen as the optimum concentration for all further analyses.

Using different addition orders of the substrate, enzyme and inhibitor (orlistat) showed different inhibition rates (\%) of pancreatic lipase (Fig. 9E). The biggest inhibition rate was shown when orlistat and lipase were prewarmed at $37{ }^{\circ} \mathrm{C}$ for $10 \mathrm{~min}$ before the addition of the substrate. This addition order ensured that there was adequate contact between the inhibitor and the lipase. This order was used in all further analyses.

\section{Figure 9 approximately here}

$\mathrm{K}_{\mathrm{m}}$, a kinetic constant, is determined by the enzyme and is not affected by the concentration. It can be obtained from Michaelis-Menten equation. Fig. 10 shows a double reciprocal plot of 1/[S] $(\mathrm{L} / \mathrm{mmol})$ and $1 / \mathrm{v}\left(10^{4} \mathrm{Ls} / \mathrm{mmol}\right)$. The absolute value of the $\mathrm{x}$-intercept is $1 / \mathrm{K}_{\mathrm{m}}$. The $\mathrm{K}_{\mathrm{m}}$ of PL 
375

376

377

378

379

380

381

382

383

384

385

386

387

388

389

390

391

392

393

394

395

396

397

398

399

400

401

calculated by our study is $1.20 \times 10^{-3} \mathrm{~mol} / \mathrm{L}$. The equation of the line fitting the data in this plot is $y=0.5639 x+0.6792$, with $R^{2}=0.9993$.

\section{Figure 10 approximately here}

\subsubsection{Inhibition of pancreatic lipase by WSC}

As shown in Fig. 11, all five WSC samples inhibited the pancreatic lipase activity dosedependently in the concentration range of $0-100 \mu \mathrm{g} / \mathrm{mL}$ in the assay system. When the substrate concentration was less than $60 \mu \mathrm{g} / \mathrm{mL}$, the inhibitory activities of WSC3, WSC4 and WSC5 were better than those of WSC2 and WSC1. There was no significant difference between the activities of WSC3, WSC4 and WSC5. When the substrate concentration was more than $60 \mu \mathrm{g} / \mathrm{mL}$, the difference became clear, as WSC3 showed the biggest inhibition rate (13.45\%). WSC4 was the second largest, with an inhibition rate of $12.19 \%$. WSC5 was the third, with an inhibition rate of $10.50 \%$. WSC2 and WSC1 were the least, with inhibition rates of $7.12 \%$ and $4.59 \%$, respectively.

In recent years, pancreatic lipase has become a valid target in the treatment of obesity, which has also attracted great interest (Wilcox et al., 2014). However, effective inhibitors with fewer side effects werestill rare. As a dietary fiber, chitosan was reported to be able to inhibit pancreatic lipase to some extent (Tsujita et al., 2007). Great attention and lots of work have been focused on its inhibitory effects. For example, studies of Sumiyoshi \& Kimura (2006) suggested that the lipidlowering effect of WSC with low Mw was better than the original chitosan and might be mediated by a decrease in the absorption of dietary lipids (triacylglycerol and cholesterol) from the small intestine as a result of the inhibition of pancreatic lipase activity. Studies by Han et al. (1999) suggested that the site of the pancreatic lipase inhibitory action of WSC mightnot be the enzyme but its substrate. The inhibitory effect of WSC on pancreatic lipase was also suggested to be related to its Mw. For example, WSC with an average molecular mass of 46,000 Da was proven to be a stronger inhibitor than the original chitosan, while WSC with an average molecular mass of 10,000 Da was proven to be a weaker inhibitor than the original chitosan (Lunagariya et al., 2014).

Although the highest inhibition rate in this study was just $13.45 \%$, which was far less than the effect of the positive control, orlistat. Samples used in this study were natural marine active 
402

403

404

405

406

407

408

409

410

411

412

413

414

415

416

417

418

419

420

421

422

423

424

425

426

427

428

429

430

substances with fewer side effects, while orlistat was a synthetic chemical that was reported to have some gastrointestinal side effects and safety risks (Wilcox et al., 2014). Studies by Sumiyoshi \& Kimura (2006) proved that WSC did not cause liver damage with the elevation of glutamic oxaloacetic transaminase and glutamic pyruvic transaminase or kidney damage with the elevation of blood nitrogen urea. Therefore, it was suggested that WSC was a safe functional food with great potential for application in anti-obesity efforts. Given that the underlying mechanism of WSC's inhibitory effect on pancreatic lipase is still not proven, the influence of the $\mathrm{Mw}$ has not been well studied and few animal or human studies have been performed, further studies are urgently needed.

\section{Figure 11 approximately here}

\section{Conclusion}

The five WSC samples used in this study exhibited great fat- and cholesterol-binding capacities. In addition, there was a significant correlation between the binding capacity and Mw of WSC, as WSC2 ( 3000 Da) showed the highest fat-binding and cholesterol-binding capacities (7.08 g.g-1 and $63.48 \mathrm{mg} \cdot \mathrm{g}^{-1}$, respectively). These capacities were much higher than those of cellulose, which were only $0.41 \mathrm{~g} . \mathrm{g}^{-1}$ and $5.95 \mathrm{mg} . \mathrm{g}^{-1}$, respectively. In addition, the binding abilities declined as the $\mathrm{Mw}$ increased or decreased from $3000 \mathrm{Da}$. Meanwhile, all WSC samples were proven to be able to inhibit pancreatic lipase activity to some extent. WSC3, WSC4 and WSC5 had higher inhibitory activities than WSC1 and WSC2 at all the tested sample concentrations.

In view of these findings, we speculate that adsorption, electrostatic binding and entrapment of the cholesterol, fat, sterols and triglycerides in food is an important anti-obesity mechanism of WSC. Given that WSC is a natural marine active substance with fewer side effects than orlistat, we believe that it will be a very promising bioactive substance in the field of obesity management. To maximize the development and utilization of WSC, further studies are necessary to investigate its underlying mechanism, anti-obesity efficacy, and bioavailability in animal and human subjects.

\section{References}

Aam BB, Heggset EB, Norberg AL, Sorlie M, Varum KM, Eijsink VGH. 2010. Production of Chitooligosaccharides and Their Potential Applications in Medicine. Marine Drugs 8:1482-1517. DOI: $10.3390 / \mathrm{md} 8051482$. 
431

432

433

434

435

436

437

438

439

440

441

442

443

444

445

446

447

448

449

450

451

452

453

454

455

456

457

458

459

460

461

462

463

464

465

466

467

468

469

470

471

Alexa E, Dragomirescu A, Pop G, Jianu C, Dragos D. 2009. The use of FT-IR spectroscopy in the identification of vegetable oils adulteration. Journal of Food Agriculture \& Environment 7:20-24.

Anraku M, Fujii T, Furutani N, Kadowaki D, Maruyama T, Otagiri M, Gebicki JM, Tomida H. 2009. Antioxidant effects of a dietary supplement: Reduction of indices of oxidative stress in normal subjects by water-soluble chitosan. Food And Chemical Toxicology 47:104-109.

Bastien M, Poirier P, Lemieux I, Després J-P. 2014. Overview of epidemiology and contribution of obesity to cardiovascular disease. Progress In Cardiovascular Diseases 56:369-381. DOI: 10.1016/j.pcad.2013.10.016.

Chang KLB, Tai MC, Cheng FH. 2001. Kinetics and products of the degradation of chitosan by hydrogen peroxide. Journal Of Agricultural And Food Chemistry 49:4845-4851. DOI: $10.1021 / \mathrm{jf001469g.}$

Choi HG, Kim JK, Kwak DH, Cho JR, Kim JY, Kim BJ, Jung KY, Choi BK, Shin MK, Choo YK. 2002. Effects of high molecular weight water-soluble chitosan on in vitro fertilization and ovulation in mice fed a high-fat diet. Archives Of Pharmacal Research 25:178-183. DOI: $10.1007 / \mathrm{BF} 02976560$.

Czechowska-Biskup R, Rokita B, Ulanski P, Rosiak JM. 2005. Radiation-induced and sonochemical degradation of chitosan as a way to increase its fat-binding capacity. Nuclear Instruments \& Methods in Physics Research Section B-Beam Interactions with Materials and Atoms 236:383-390. DOI: 10.1016/j.nimb.2005.04.002.

Deleris GY, Petibois C. 2002. Applications of FT-IR spectrometry to plasma contents analysis and monitoring. In: MahadevanJansen A, Mantsch HH, and Puppels GJ, eds. Biomedical Vibrational Spectroscopy Ii. Bellingham: Spie-Int Soc Optical Engineering, 70-78. DOI: 10.1016/S0924-2031(03)00053-5.

Derosa G, Cicero AFG, Murdolo G, Piccinni MN, Fogari E, Bertone G, Ciccarelli L, Fogari R. 2005. Efficacy and safety comparative evaluation of orlistat and sibutramine treatment in hypertensive obese patients. Diabetes Obesity \& Metabolism 7:47-55. DOI: 10.1111/j.1463-1326.2004.00372.x.

Feller G, Thiry M, Arpigny JL, Gerday C. 1991. Cloning and expression in Escherichia coli of three lipase-encoding genes from the psychrotrophic antarctic strain Moraxella TA144. Gene 102:111-115. DOI: 10.1016/0378-1119(91)90548-P.

Gu Y, Hurst WJ, Stuart DA, Lambert JD. 2011. Inhibition of key digestive enzymes by cocoa extracts and procyanidins. Journal Of Agricultural And Food Chemistry 59:5305-5311. DOI: $10.1021 /$ jf200180n.

Han LK, Kimura Y, Okuda H. 1999. Reduction in fat storage during chitin-chitosan treatment in mice fed a high-fat diet. International Journal Of Obesity 23:174-179. DOI: 10.1038/sj.ijo.0800806.

Howarth NC, Saltzman E, Roberts SB. 2001. Dietary fiber and weight regulation. Nutrition Reviews 59:129-139.

Hu XQ, Tao NP, Wang XC, Xiao JB, Wang MF. 2016. Marine-derived bioactive compounds 
with anti-obesity effect: A review. Journal of Functional Foods 21:372-387. DOI: 10.1016/j.jff.2015.12.006.

Ishimoto R, Sugimoto M, Kawai F. 2001. Screening and characterization of trehalose-oleate hydrolyzing lipase. Fems Microbiology Letters 195:231-235. DOI: 10.1111/j.15746968.2001.tb10526.x.

Kaats GR, Michalek JE, Preuss HG. 2006. Evaluating efficacy of a chitosan product using a double-blinded, placebo-controlled protocol. Journal of The American College Of Nutrition 25:389-394.

Kanauchi O, Deuchi K, Imasato Y, Shizukuishi M, Kobayashi E. 1995. Mechanism for the inhibition of fat digestion by chitosan and for the synergistic effect of ascorbate. Bioscience Biotechnology And Biochemistry 59:786-790.

Kumar SG, Rahman MA, Lee SH, Hwang HS, Kim HA, Yun JW. 2009. Plasma proteome analysis for anti-obesity and anti-diabetic potentials of chitosan oligosaccharides in ob/ob mice. Proteomics 9:2149-2162. DOI: 10.1002/pmic.200800571.

Li KC, Xing RE, Liu S, Qin YK, Meng XT, Li PC. 2012. Microwave-assisted degradation of chitosan for a possible use in inhibiting crop pathogenic fungi. International Journal of Biological Macromolecules 51:767-773. DOI: 10.1016/j.ijbiomac.2012.07.021.

Liu J, Zhang J, Xia W. 2008. Hypocholesterolaemic effects of different chitosan samples in vitro and in vivo. Food Chemistry 107:419-425. DOI: 10.1016/j.foodchem.2007.08.044.

Lunagariya NA, Patel NK, Jagtap SC, Bhutani KK. 2014. Inhibitors of pancreatic lipase: State of the art and clinical perspectives. Excli Journal 13:897-921.

Margesin R, Feller G, Hammerle M, Stegner U, Schinner F. 2002. A colorimetric method for the determination of lipase activity in soil. Biotechnology Letters 24:27-33. DOI: 10.1023/A:1013801131553.

Muzzarelli RAA, Terbojevich M, Muzzarelli C, Francescangeli O. 2002. Chitosans depolymerized with the aid of papain and stabilized as glycosylamines. Carbohydrate Polymers 50:69-78. DOI: 10.1016/S0144-8617(01)00378-2.

Neyrinck AM, Bindels LB, De Backer F, Pachikian BD, Cani PD, Delzenne NM. 2009. Dietary supplementation with chitosan derived from mushrooms changes adipocytokine profile in diet-induced obese mice, a phenomenon linked to its lipid-lowering action. International Immunopharmacology 9:767-773. DOI: 10.1016/j.intimp.2009.02.015

Ogden CL, Carroll MD, Kit BK, Flegal KM. 2014. Prevalence of childhood and adult obesity in the United States, 2011-2012. Jama 311:806-814. DOI: 10.1001/jama.2014.732.

Peniche C, Argüelles-Monal W, Davidenko N, Sastre R, Gallardo A, San Román J. 1999. Self-curing membranes of chitosan/PAA IPNs obtained by radical polymerization: preparation, characterization and interpolymer complexation. Biomaterials 20:1869-1878. DOI: $10.1016 / \mathrm{S} 0142-9612(99) 00048-4$.

Qinna NA, Akayleh FT, Al Remawi MM, Kamona BS, Taha H, Badwan AA. 2013. Evaluation of a functional food preparation based on chitosan as a meal replacement diet. Journal of Functional Foods 5:1125-1134. DOI: 10.1016/j.jff.2013.03.009.

Racette SB, Deusinger SS, and Deusinger RH. 2003. Obesity: overview of prevalence, etiology, 
513

514

515

516

517

518

519

520

521

522

523

524

525

526

527

528

529

530

531

532

533

534

535

536

537

538

539

540

541

542

543

544

545

546

547

548

549

550

551

552

553

and treatment. Physical Therapy 83:276-288.

Rahman MA, Kumar SG, Kim SW, Hwang HJ, Baek YM, Lee SH, Hwang HS, Shon YH, Nam KS, Yun JW. 2008. Proteomic analysis for inhibitory effect of chitosan oligosaccharides on 3T3-L1 adipocyte differentiation. Proteomics 8:569-581. DOI: 10.1002/pmic.200700888.

Rahmouni K, Correia MLG, Haynes WG, Mark AL. 2005. Obesity-associated hypertensionNew insights into mechanisms. Hypertension 45:9-14. DOI: 10.1161/01.HYP.0000151325.83008.b4

Rodgers RJ, Tschöp MH, Wilding JP. 2012. Anti-obesity drugs: past, present and future. Disease Models and Mechanisms 5:621-626. DOI: 10.1242/dmm.009621.

Saltiel AR, Kahn CR. 2001. Insulin signalling and the regulation of glucose and lipid metabolism. Nature 414:799-806. DOI: 10.1038/414799a

Slavin JL. 2005. Dietary fiber and body weight. Nutrition 21:411-418. DOI: 10.1016/j.nut.2004.08.018.

Sumiyoshi M, Kimura Y. 2006. Low molecular weight chitosan inhibits obesity induced by feeding a high-fat diet long-term in mice. Journal Of Pharmacy And Pharmacology 58:201-207. DOI: 10.1211/jpp.58.2.0007

Tobias DK, Pan A, Jackson CL, O'Reilly EJ, Ding EL, Willett WC, Manson JE, Hu FB. 2014. Body-Mass Index and Mortality among Adults with Incident Type 2 Diabetes. New England Journal Of Medicine 370:233-244. DOI: 10.1056/NEJMoa1304501

Trombotto S, Ladaviere C, Delolme F, Domard A. 2008. Chemical preparation and structural characterization of a homogeneous series of chitin/chitosan oligomers. Biomacromolecules 9:1731-1738. DOI: 10.1021/bm800157x

Tsujita T, Takaichi H, Takaku T, Sawai T, Yoshida N, Hiraki J. 2007. Inhibition of lipase activities by basic polysaccharide. Journal of Lipid Research 48:358-365. DOI: 10.1194/j1r.M600258-JLR200

Van Itallie TB. 1978. Dietary fiber and obesity. The American journal of clinical nutrition 31:S43S52.

Vucenik I, Stains JP. 2012. Obesity and cancer risk: evidence, mechanisms, and recommendations. In: Surh YJ, Song YS, Han JY, Jun TW, and Na HK, eds. Nutrition and Physical Activity in Aging, Obesity, and Cancer. Oxford: Blackwell Science Publ, 37-43. DOI: 10.1111/j.1749-6632.2012.06750.x.

Wilcox MD, Brownlee IA, Richardson JC, Dettmar PW, Pearson JP. 2014. The modulation of pancreatic lipase activity by alginates. Food Chemistry 146:479-484. DOI: 10.1016/j.foodchem.2013.09.075

Wojtasz-Pajak A, Kolodziejska I, Debogorska A, Malesa-Ciecwierz M. 1998. Enzymatic, physical and chemical modifications of krill chitin. Bulletin of the Sea Fisheries Institute 1.

Xia WS, Liu P, Zhang JL, Chen J. 2011. Biological activities of chitosan and chitooligosaccharides. Food Hydrocolloids 25:170-179. DOI: 10.1016/j.foodhyd.2010.03.003 
554 Zhang JL, Zhang W, Mamadouba B, Xia WS. 2012. A comparative study on hypolipidemic

555

556

557

558

559

560

561

562

563

564

565

566

567

568

569

570

571

572

573

574

575

576

577

578

579

580

581 activities of high and low molecular weight chitosan in rats. International Journal of Biological Macromolecules 51:504-508. DOI: 10.1016/j.ijbiomac.2012.06.018

Zou P, Li K, Liu S, Xing R, Qin Y, Yu H, Zhou M, Li P. 2015. Effect of chitooligosaccharides with different degrees of acetylation on wheat seedlings under salt stress. Carbohydrate Polymers 126:62-69. DOI: 10.1016/j.carbpol.2015.03.028

\section{Figures}




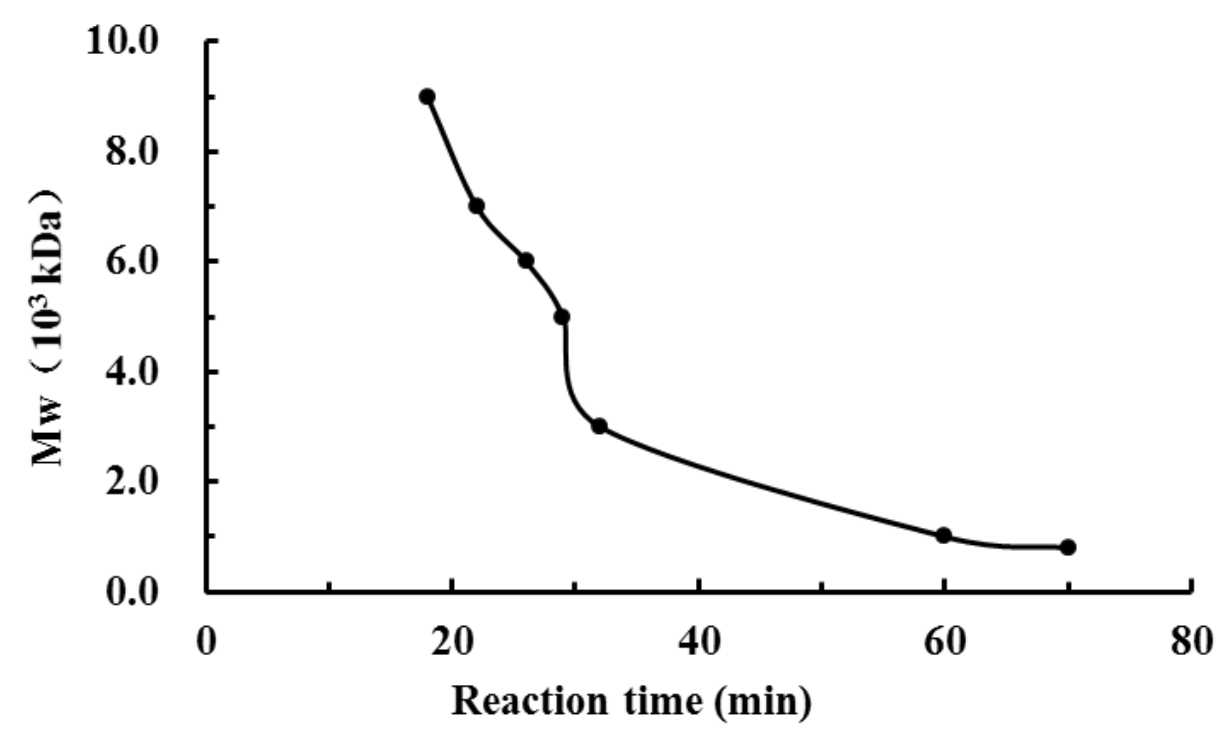

582

583

584

585

586

587

588

589

590

591

592

593

594

595

596

597

598

599

600

601

602

Figure 1 The effect of reaction time on the degradation of chitosan under the conditions of $\mathrm{H}_{2} \mathrm{O}_{2}$ assisted with microwave irradiation. CTSO $(5 \mathrm{~g})$ was introduced to $250 \mathrm{~mL}$ of $2 \%$ acetic acid, and then $5 \mathrm{~mL}$ of $30 \% \mathrm{H}_{2} \mathrm{O}_{2}$ was added. Afterwards, assisted with microwave radiation, the degradation was carried out at a power of $600 \mathrm{~W}$ at $70{ }^{\circ} \mathrm{C}$ for $60,32,30,22$ and $18 \mathrm{~min}$, respectively. The weight-average molecular weight was measured by HPLC.

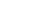



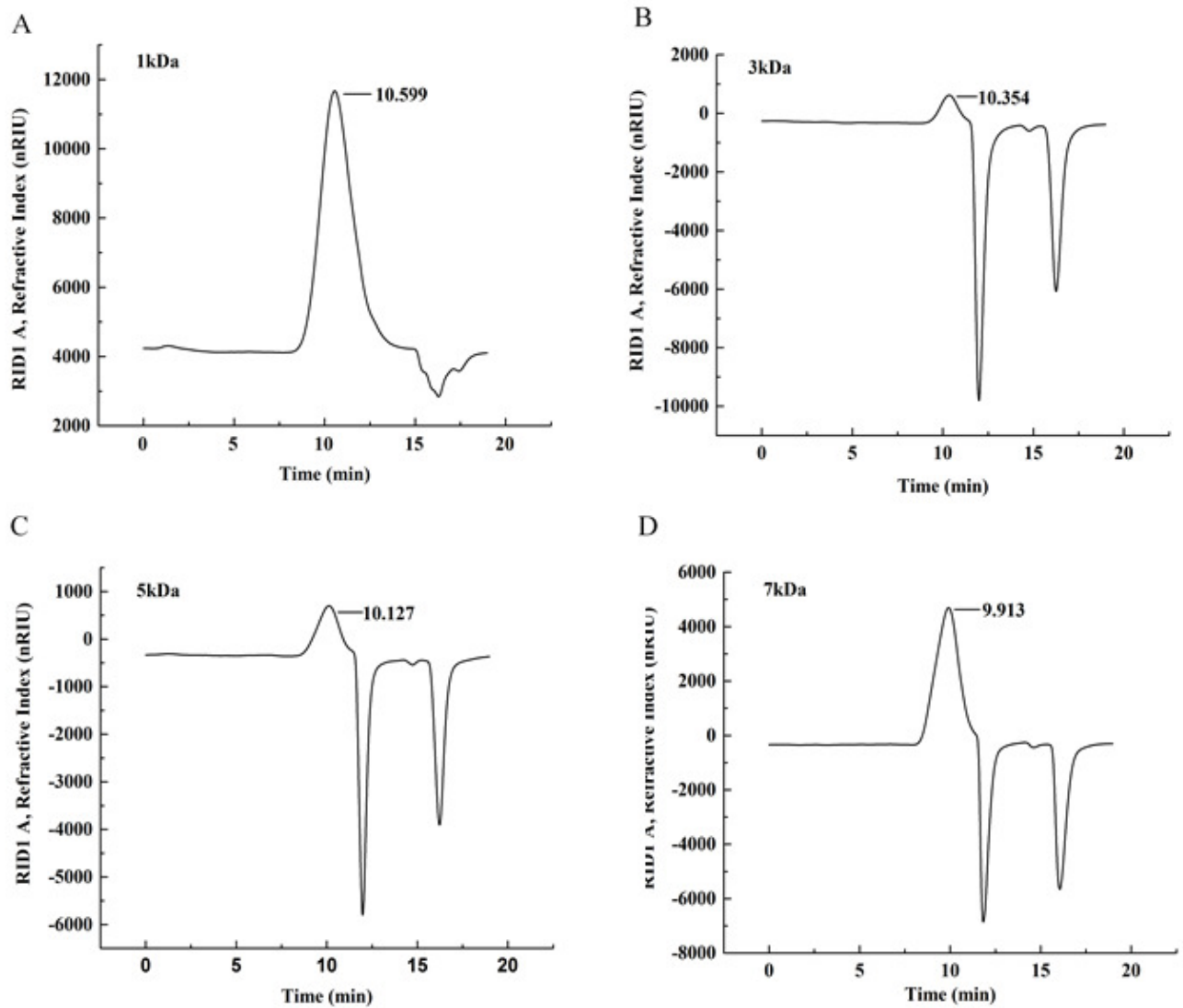

E

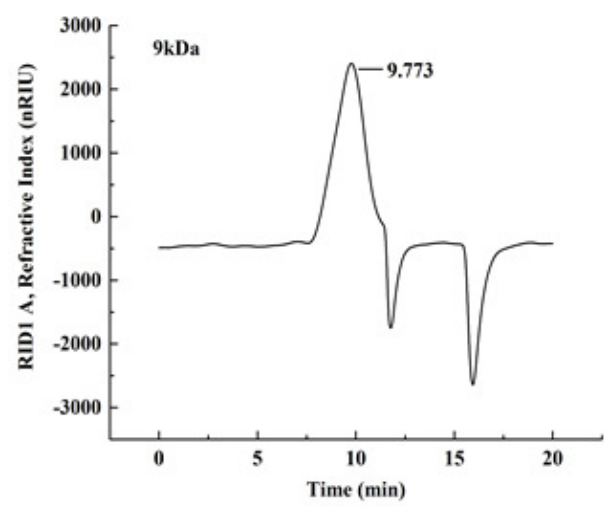

603

604

605

606

607

608

609

610

611

612
Figure 2 The weight-average molecular weight assay of WSC1-5 with HPLC. The retention time and weight-average molecular weight of (A) WSC1, (B) WSC2, (C) WSC3, (D) WSC4 and (E) WSC5 were measured by an Agilent 1260 gel permeation chromatography equipped with a refractive index detector. Chromatography was performed on TSK G3000-PWXL columns, using $0.2 \mathrm{M} \mathrm{CH}_{3} \mathrm{COOH} / 0.1 \mathrm{M} \mathrm{CH}_{3} \mathrm{COONa}$ aqueous solution as the mobile phase at a flow rate of 0.8 $\mathrm{mL} / \mathrm{min}$ with a column temperature of $30^{\circ} \mathrm{C}$. The sample concentration was $0.3 \%(\mathrm{w} / \mathrm{v})$. The standards used to calibrate the column were dextrans with Mw of 1000, 5000, 12000, 25000 and 50000 Da. 


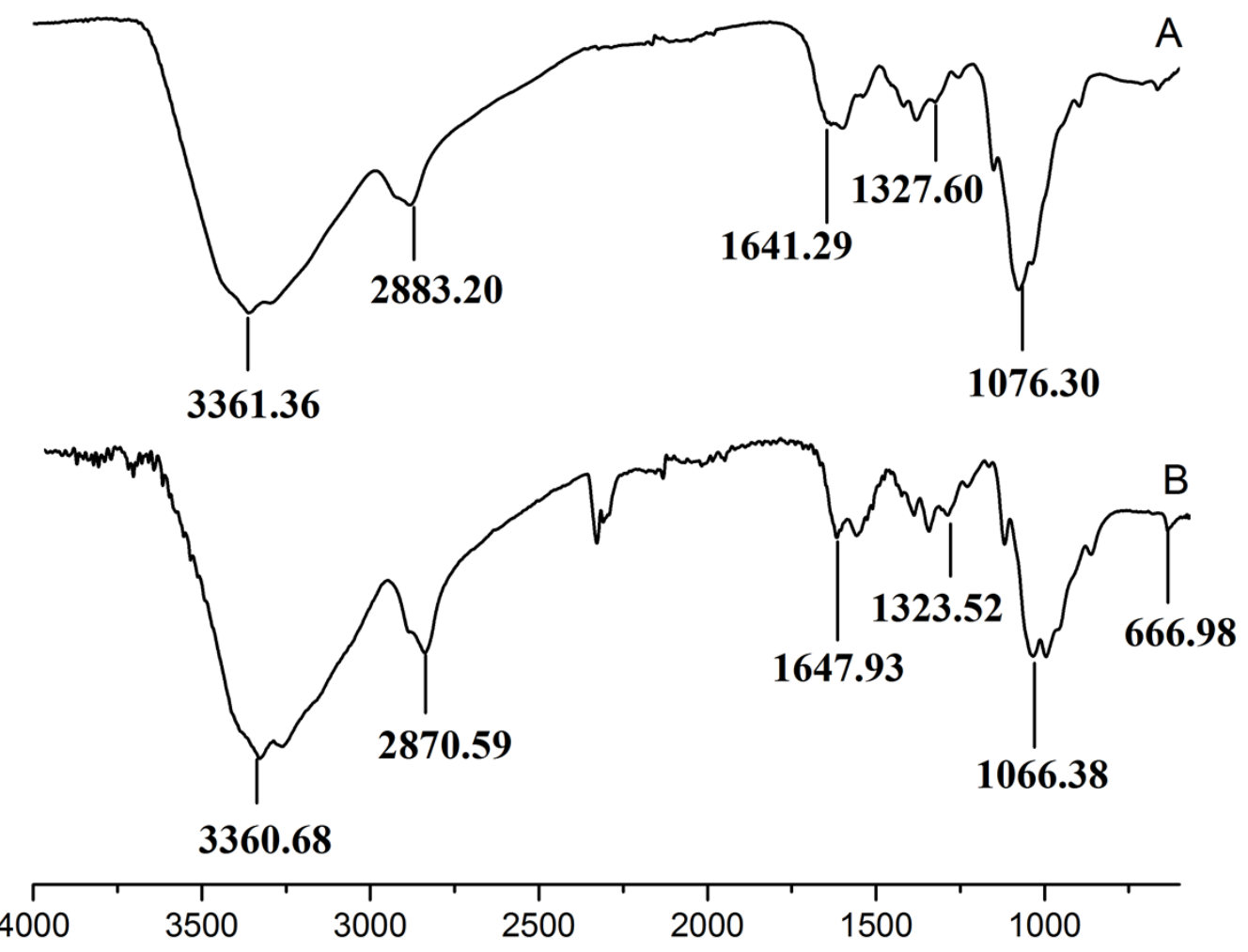

613

614

615

616

617

618

619

620

621

Fig. 3. FT-IR spectra of (A) original chitosan, $(\hat{B})$ the degraded chitosan. 


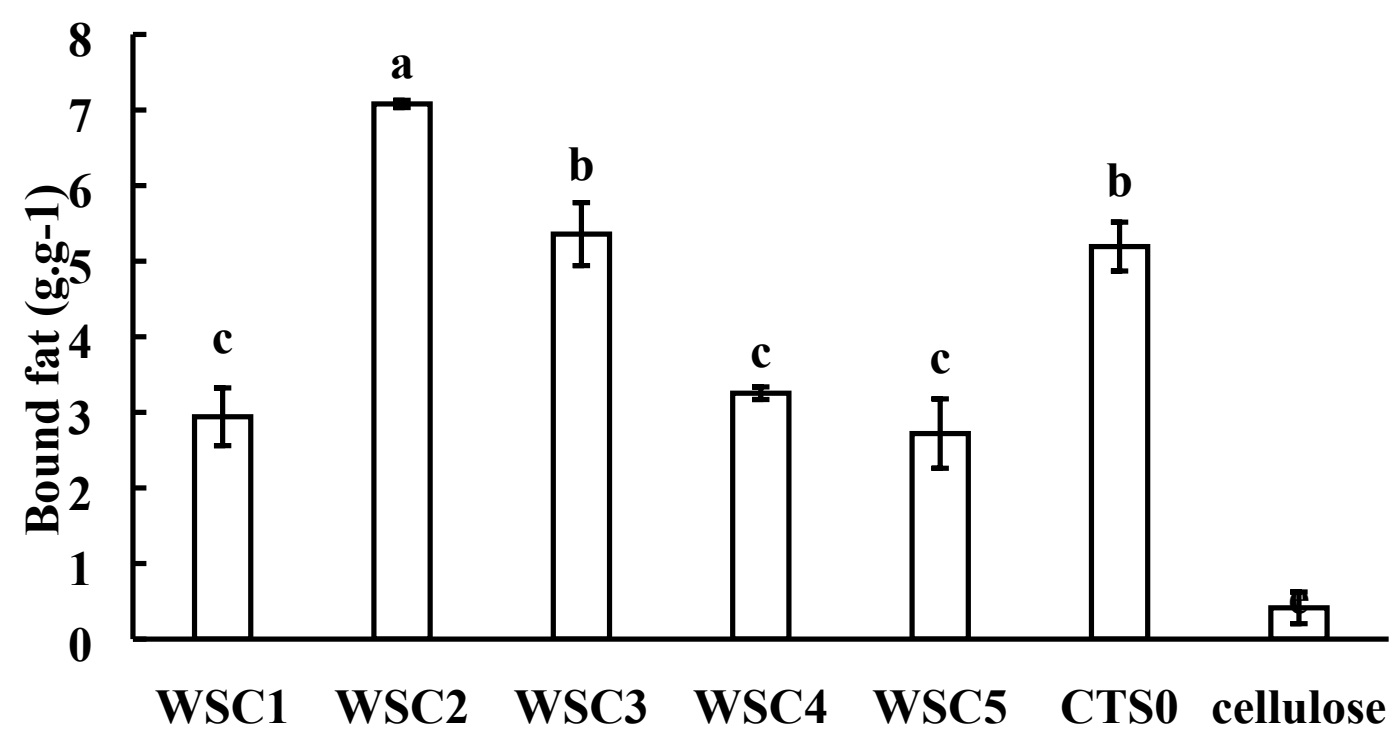

Figure 4 Fat-binding capacities of WSC1-5, CTS0 and cellulose in vitro. The mixture of WSC (or chitosan), $\mathrm{HCl}$ and peanut oil was swirled thoroughly and incubated for $2 \mathrm{~h}$ at $37{ }^{\circ} \mathrm{C}$ and 300 rpm. Then, the $\mathrm{pH}$ was adjusted to the range of 7.0-7.60 and incubated for another $2 \mathrm{~h}$ at $37^{\circ} \mathrm{C}$ and $300 \mathrm{rpm}$. Afterwards, the sample was cooled to room temperature and centrifuged at $3740 \times \mathrm{g}$ for $20 \mathrm{~min}$. Then, the supernatant oil was removed, and $\mathrm{HCl}$ solution was added until the $\mathrm{pH}$ was 3.0. After double extraction of the sample with ethyl ether, the combined ether extracts were kept at $40{ }^{\circ} \mathrm{C}$ until complete evaporation of ether. The remaining oil was weighed. The fat-binding capacity of the WSC sample was expressed as grams of bound oil per gram of WSC. Cellulose was used as a positive control, and the solution without WSC was used as a substrate blank. Data are expressed as the mean $\pm \mathrm{SD}$ from triplicate experiments. Different small letters next to values indicate significant differences $(\mathrm{p}<0.05)$. 


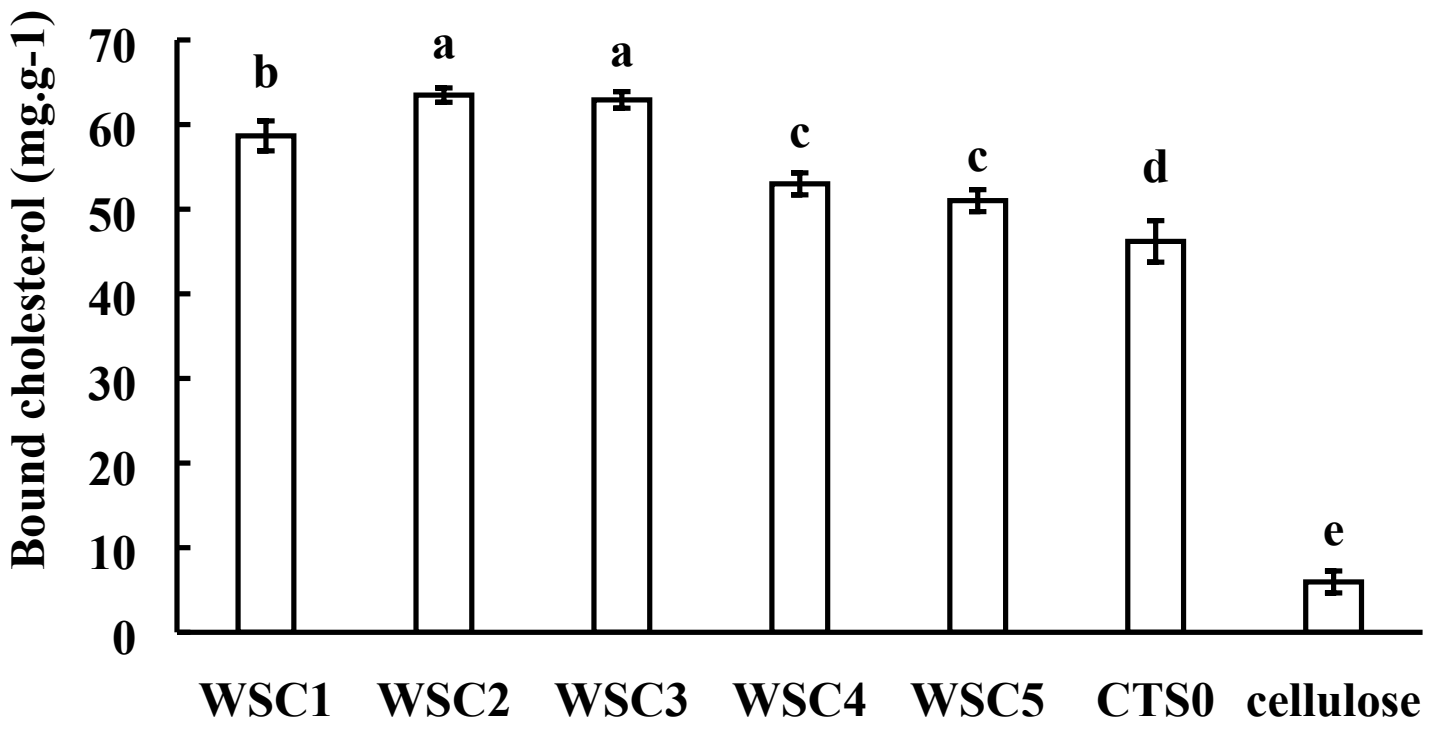

634

635

636

637

638

639

640

641

642

643

644

645

646

647

648

649

650

\section{4}

5

47

Figure 5 Cholesterol-binding capacities of WSC1-5, CTS0 and cellulose in vitro. The mixture of WSC (or chitosan) and the cholesterol micellar solution was incubated for $2 \mathrm{~h}$ in a $37^{\circ} \mathrm{C}$ shaker bath and then centrifuged at $23294 \times \mathrm{g}$ for $20 \mathrm{~min}$ at $37^{\circ} \mathrm{C}$. The amount of binding was calculated as the amount of cholesterol in the supernatant of the substrate blank subtracted from the amount in the supernatant of the sample. The amount of cholesterol was determined by the total cholesterol assay kit. The binding capacity of WSC was calculated as milligrams of bound cholesterol per gram of WSC. Cellulose was used as a positive control, while the micellar solution without WSC was used as a substrate blank. Data are expressed as the mean \pm SD from triplicate experiments. Different small letters next to values indicate significant differences $(p<0.05)$. 

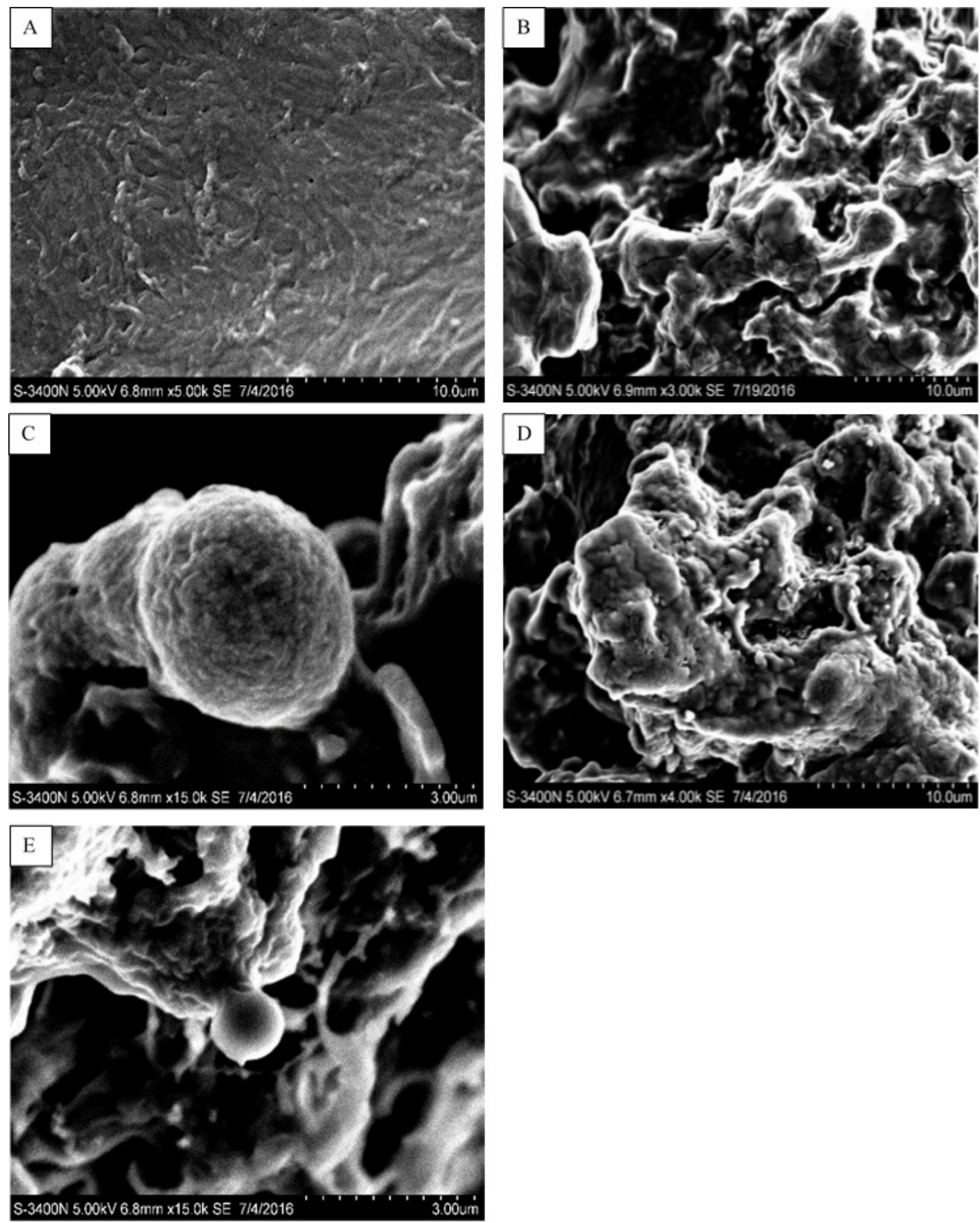

Figure 6 SEM images of WSC2, the precipitate formed by WSC2 and peanut oil, and the

653 precipitate formed by WSC2 and cholesterol. SEM of (A) WSC2, (B) the precipitate formed by

WSC2 and peanut oil, (C) obvious microspheres in the precipitate formed by WSC2 and peanut oil, (D) the precipitate formed by WSC2 and cholesterol, and (E) obvious microspheres in the

656 precipitate formed by WSC2 and cholesterol. 
657

658

659

660

661

662

663

664
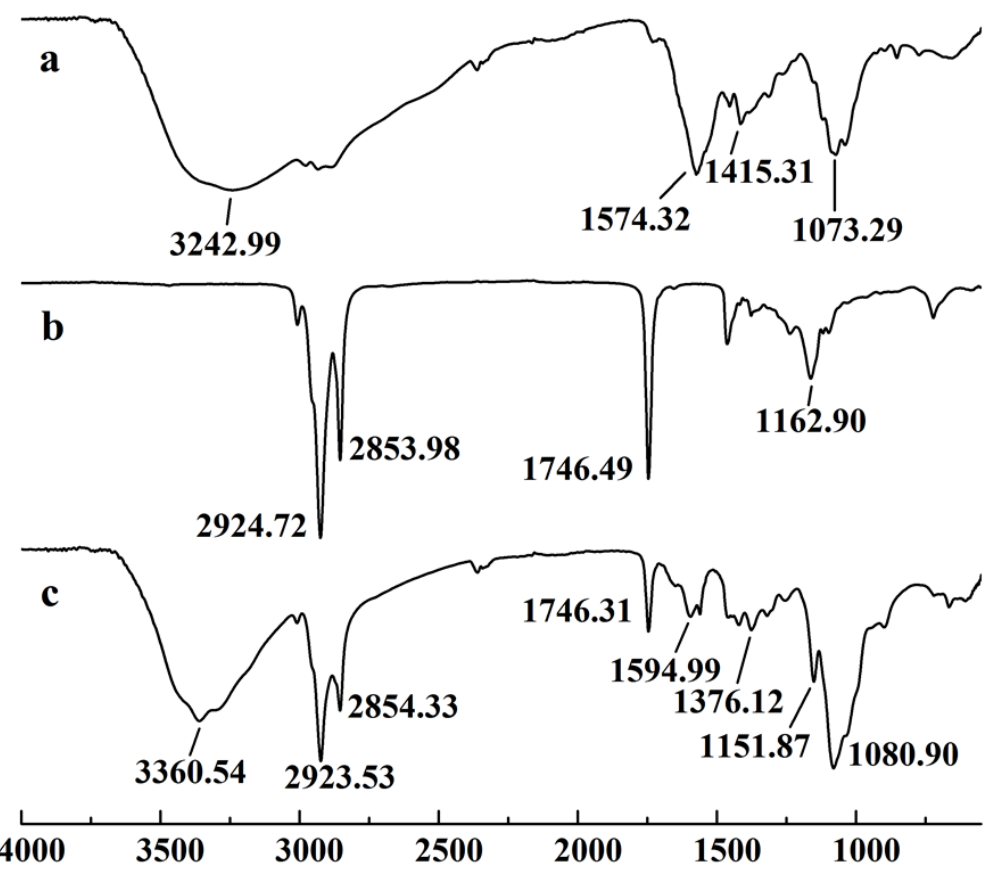

Figure 7 FT-IR spectra of WSC2, peanut oil and the precipitate collected after centrifugation. The FT-IR spectra of (a) WSC2, (b) peanut oil, and (c) the precipitate collected after centrifugation. 


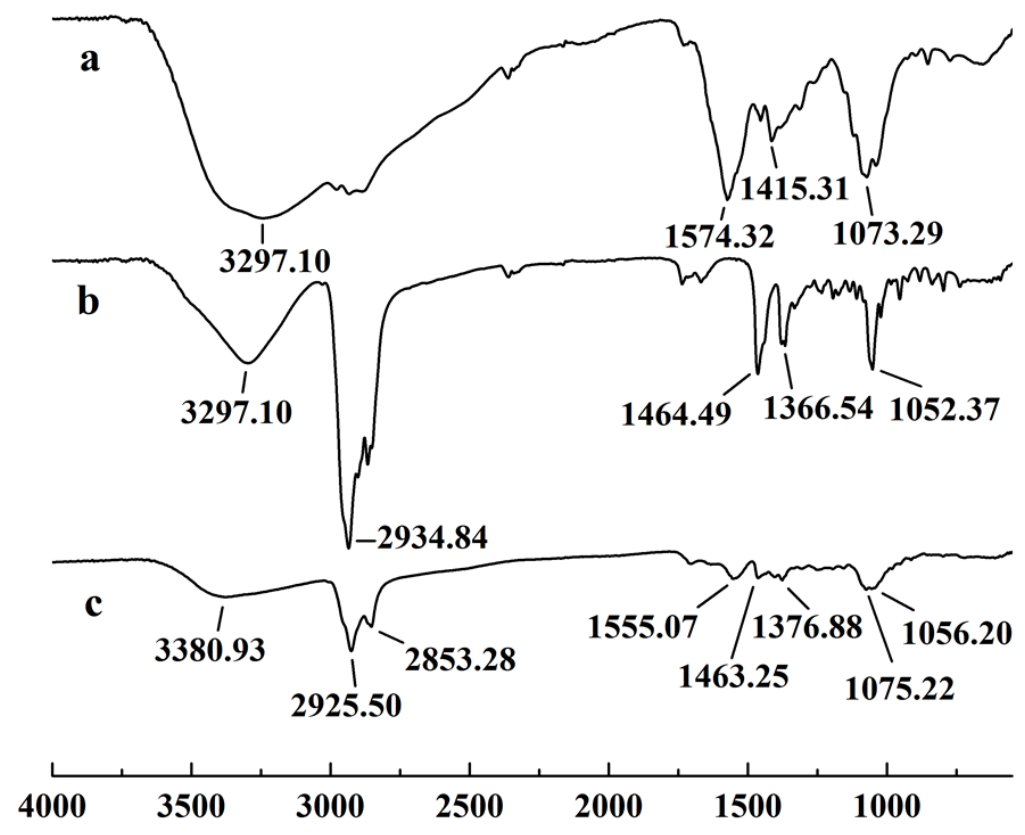

665

Figure 8 FT-IR spectra of WSC2, cholesterol and the precipitate collected after centrifugation. The FT-IR spectra of (a) WSC2, (b) cholesterol, and (c) the precipitate collected after centrifugation.

669

670

671

672

673

674

675

676

677

678

679

680

681 

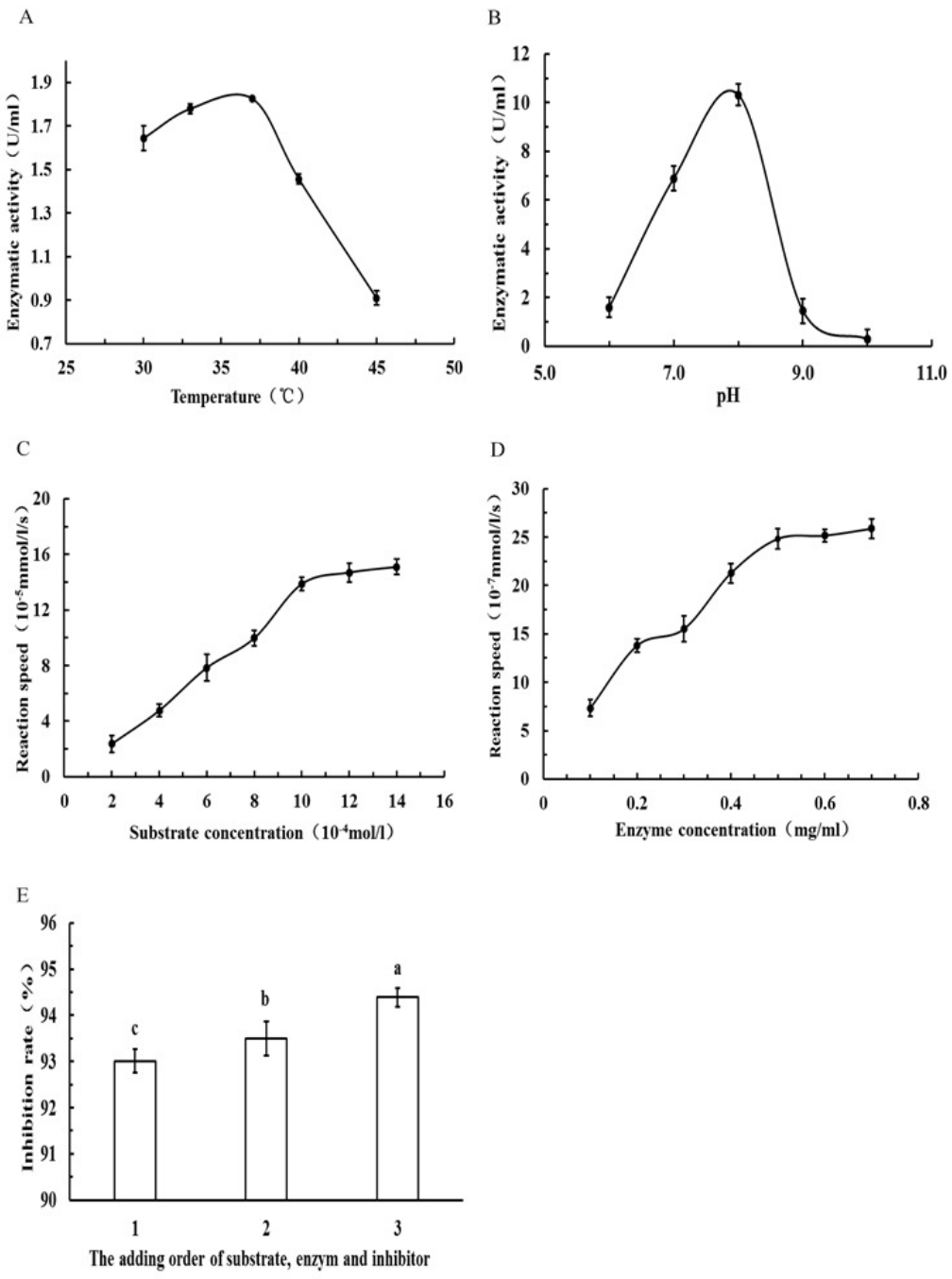

682

Figure 9 Estimation of the optimum reaction conditions for PL. The effect of (A) reaction temperature, $(\mathrm{B})$ reaction $\mathrm{pH}$ on $\mathrm{PL}$ enzymatic activity $(\mathrm{U} / \mathrm{mL}),(\mathrm{C})$ substrate concentration, and (D) enzyme concentration on reaction speed $\left(10^{-5} \mathrm{mmol} / \mathrm{l} / \mathrm{g}\right)$, and the addition order of reagents on PL activity inhibition rate (\%) (1: substrate and enzyme were prewarmed at $37^{\circ} \mathrm{C}$ for 10 min first, and then the inhibitor was added; 2: substrate and inhibitor were prewarmed at $37^{\circ} \mathrm{C}$ for $10 \mathrm{~min}$ first, and then the enzyme was added; 3: inhibitor and enzyme were prewarmed at $37{ }^{\circ} \mathrm{C}$ for 10 min first, and then the substrate was added) were determined by colorimetric methods using pNPB) as a chromogenic substrate. Data are expressed as the mean \pm SD from triplicate experiments. Different small letters next to values indicate significant differences $(p<0.05)$. 


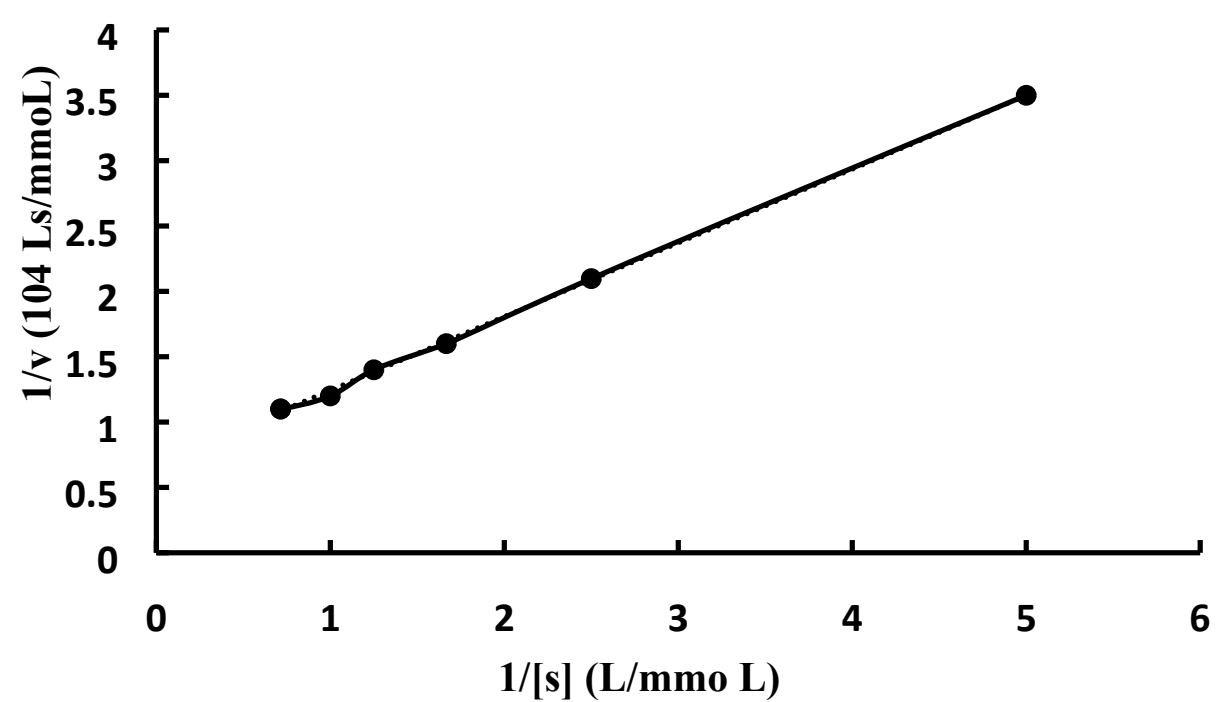

692

693

694

695

696

697

698

699

700

701

702

703

704

705

706

707

708

709

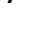

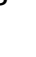

Figure 10 Double reciprocal plot of $1 /[\mathrm{S}](\mathrm{L} / \mathrm{mmol})$ and $1 / \mathbf{v}\left(10^{4} \mathrm{Ls} / \mathrm{mmol}\right)$. PL and pNPB were mixed and incubated in the water bath at $37^{\circ} \mathrm{C}$ for exactly $15 \mathrm{~min}$. Then, immediately, the contents were cooled for $10 \mathrm{~min}$ on ice to stop the reaction and centrifuged at $3740 \times \mathrm{g}$ and in the range of 2 to $4{ }^{\circ} \mathrm{C}$ for $5 \mathrm{~min}$. The supernatants were pipetted to measure the absorbance of the released pNP spectrophotometrically at $405 \mathrm{~nm}$ against the reagent blank. Data are expressed as the mean $\pm \mathrm{SD}$ from triplicate experiments. Different small letters next to values indicate significant differences $(\mathrm{p}<0.05)$.

(1)

(1)

(1)

5

6




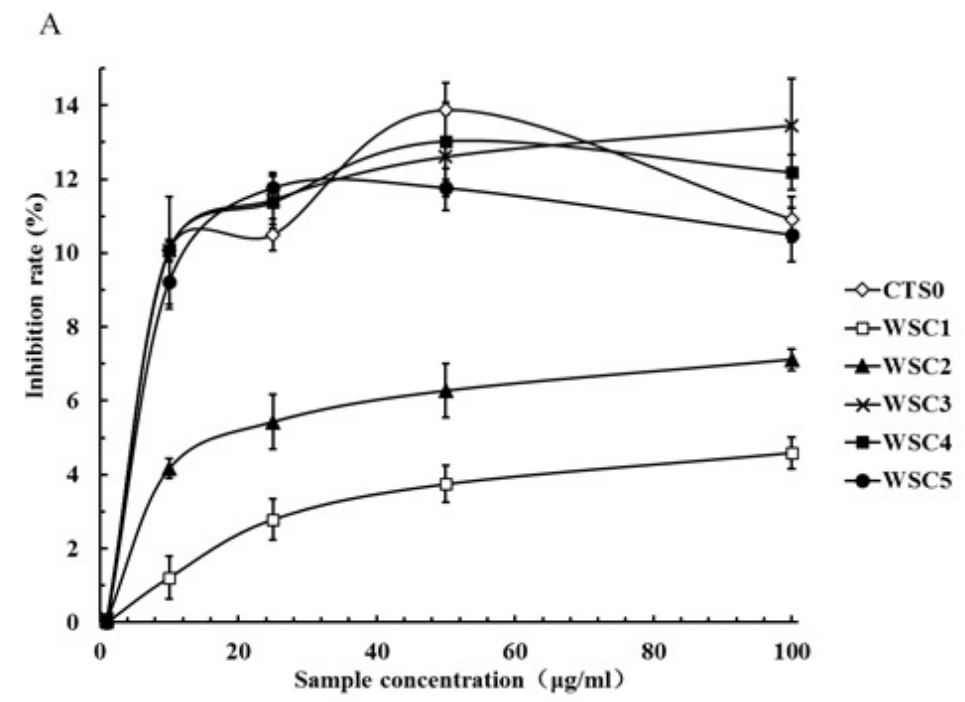

B

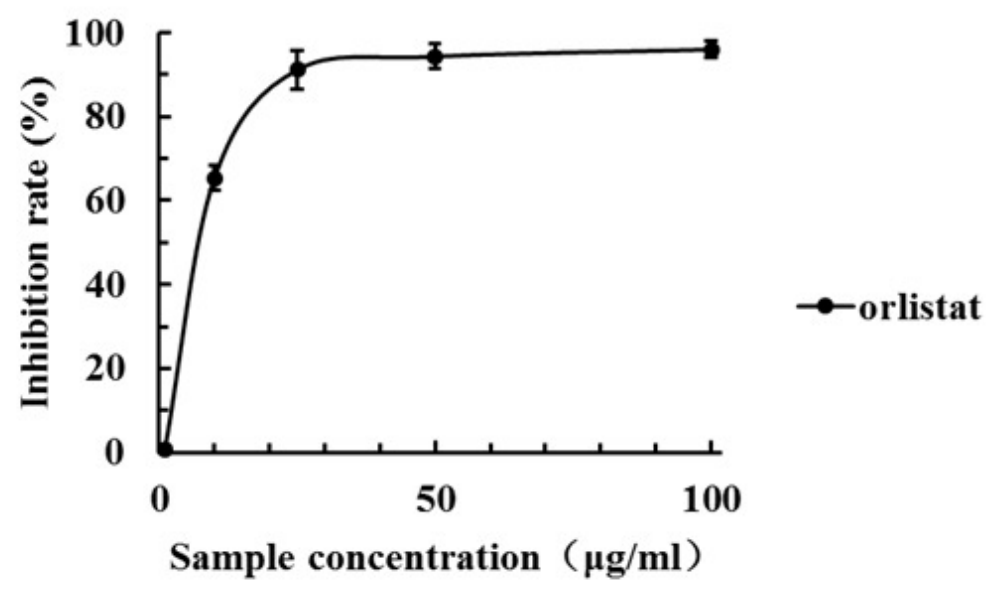

710

711 Figure 11 Inhibition rate (\%) of PL by WSC1-5, CTS0 and orlistat. The inhibition rate (\%) of

712 PL by (A) WSC1-5, CTS and (B) orlistat were determined by colorimetric methods using PNPB

713 as the chromogenic substrate. Data are expressed as the mean \pm SD from triplicate experiments.

714 Different small letters next to values indicate significant differences $(\mathrm{p}<0.05)$. 